\title{
Contemporary Review of Smartphone Apps for Tinnitus Management and Treatment
}

\author{
Muntazir Mehdi ${ }^{1, *(\mathbb{D},}$, Albi Dode ${ }^{2}$, Rüdiger Pryss ${ }^{3}\left(\mathbb{D}\right.$, Winfried Schlee ${ }^{4}$, Manfred Reichert ${ }^{2}$ \\ and Franz J. Hauck ${ }^{1}$ * \\ 1 Institute of Distributed Systems, Ulm University, 89081 Ulm, Germany \\ 2 Institute of Databases and Information Systems, Ulm University, 89081 Ulm, Germany; \\ albi.dode@uni-ulm.de (A.D.); manfred.reichert@uni-ulm.de (M.R.) \\ 3 Institute of Clinical Epidemiology and Biometry, University of Würzburg, 97070 Würzburg, Germany; \\ ruediger.pryss@uni-wuerzburg.de \\ 4 Clinic and Polyclinic for Psychiatry and Psychotherapy, 93053 Regensburg, Germany; \\ winfried.schlee@tinnitusresearch.org \\ * Correspondence: muntazir.mehdi@uni-ulm.de (M.M.); franz.hauck@uni-ulm.de (F.J.H.)
}

Received: 24 September 2020; Accepted: 9 November 2020; Published: 17 November 2020

\begin{abstract}
Tinnitus is a complex and heterogeneous psycho-physiological disorder responsible for causing a phantom ringing or buzzing sound albeit the absence of an external sound source. It has a direct influence on affecting the quality of life of its sufferers. Despite being around for a while, there has not been a cure for tinnitus, and the usual course of action for its treatment involves use of tinnitus retaining and sound therapy, or Cognitive Behavioral Therapy (CBT). One positive aspect about these therapies is that they can be administered face-to-face as well as delivered via internet or smartphone. Smartphones are especially helpful as they are highly personalized devices, and offer a well-established ecosystem of apps, accessible via respective marketplaces of differing mobile platforms. Note that current therapeutic treatments such as CBT have shown to be effective in suppressing the tinnitus symptoms when administered face-to-face, their effectiveness when being delivered using smartphones is not known so far. A quick search on the prominent market places of popular mobile platforms (Android and iOS) yielded roughly 250 smartphone apps offering tinnitus-related therapies and tinnitus management. As this number is expected to steadily increase due to high interest in smartphone app development, a contemporary review of such apps is crucial. In this paper, we aim to review scientific studies validating the smartphone apps, particularly to test their effectiveness in tinnitus management and treatment. We use the PRISMA guidelines for identification of studies on major scientific literature sources and delineate the outcomes of identified studies.
\end{abstract}

Keywords: mobile health; healthcare; mobile apps; tinnitus therapy; cbt; self help; tinnitus research

\section{Introduction}

Tinnitus is a disorder or condition mainly associated with the perception of a continuous ringing sound or noise in the ears. Importantly, the phantom auditory sensation exists in absence of any external sound source. Multiple causes for tinnitus have been identified with hearing loss being one of the most important risk factors for tinnitus. Tinnitus affects approximately 15\% of the world's population. Note that for $2 \%$ of its sufferers tinnitus can be enfeebling [1]. Presently, tinnitus is regarded as a condition that involves changes at different levels of the auditory pathway and the auditory nervous system. Changes in 
tinnitus may also be influenced by psycho-social stress (for example, negative thoughts, work or home related stress, etc.) affecting the emotional status and the auditory system [2,3].

Furthermore, patients who perceive tinnitus also report variations in tinnitus loudness and tinnitus-related distress, as well as individual perception of tinnitus [4]. Some influencing factors of this variability are known [4-6], however, most of the causative factors for this variability within the tinnitus population are still unknown. For instance, the tinnitus perception variability can be attributed to changes in the atmospheric surroundings [7] and environmental conditions of the patient [8]. Smartphone-based Ecological Momentary Assessments methods can be helpful in better understanding the tinnitus variability in larger tinnitus populations [9].

Given the current understanding of tinnitus, researchers within the tinnitus community are also investigating smartphone-based solutions for mobile diagnosis, event detection, treatment, and monitoring of patients. Recently, smartphone-based solutions such as smartphone apps have gained significant recognition due to popularity of smart sensors such as mobile brain-imaging techniques, and auxiliary health devices like heart meters and smart wristbands within healthcare [10,11]. Furthermore, smartphone application marketplaces provide an ecosystem that can be easily extended with new apps. The antecedent interest of the research community in closely-related health complications of tinnitus like stress [12-15], Meniere's disease [8,16], hearing loss [17-19], vertigo [20-22], or dementia [23,24] affirms an imminent inclusion of smartphone apps for tinnitus too.

Note that further research to determine the effectiveness of smartphone apps in different domains of healthcare is indispensable $[25,26]$, as there is an indication that the smartphone apps can help patients in maintaining and mitigating their health problems [27-29]. Similarly, for tinnitus there exists a plethora of smartphone apps to help patients in mitigating and managing their tinnitus symptoms [30]. Although there has not been a cure or treatment for tinnitus, the usual course of action for treatment of tinnitus involves use of tinnitus retaining, sound, or cognitive behavioral therapies [1]. Although the current mode of tinnitus treatment involves face-to-face administration of the aforementioned therapies, however, they can also be administered using smartphones.

Consequently, in recent years, there has been a notable interest in development of smartphone apps aiming at helping patients for management and treatment of their tinnitus [30]. Few attempts on objective quality assessment of tinnitus-related smartphones apps have been reported [30], the clinical effectiveness of these smartphone apps within the context of tinnitus is still questionable. Although existing literature poses many articles reviewing healthcare apps in a more general context [31], very limited literature exists with a specific focus on tinnitus. While Internet or smartphone based CBT has been critically reviewed [32,33], and its effectiveness has been well-documented and established [34], research on reviewing the effectiveness of smartphone apps offering other therapies such as tinnitus therapy, tinnitus retaining therapy, or sound therapy is still scarce. In terms of tinnitus-related therapies to control tinnitus symptoms, Piskosz [35] highlights the use of sound-related therapy. Hesse [36] aims to assess and review smartphone-app-supported therapies for tinnitus and Deshpande and Shimunova [37] presents an evaluation by highlighting the features of smartphone apps. With the fast-growing development and new apps being developed and published in app market-places, an up-to-date review can contribute significantly to the body of knowledge.

Hence, in this article, we provide a detailed review of studies that have evaluated tinnitus apps, specifically in terms of their effectiveness for tinnitus management and treatment. In particular, we take advantage of the PRISMA guidelines [38] for identification of scientific studies. To do so, we have structured the article as follows: the overall review process is highlighted in Section 2, while the identified results are reported in Section 3 and discussed in Section 4. Before concluding the article, the limitations and potential future directions of proposed review are reported in Section 5. 


\section{Methods}

Several relevant sources for scientific literature were queried for identification of relevant literature based on the PRISMA guidelines. The overall process of identifying, screening, testing for eligibility, and final inclusion of relevant literature is illustrated in Figure 1. The sources were queried with the criteria of finding relevant literature from 2017 onward. The searches were conducted in two separate cycles at different dates-(1) 15 May 2019, and (2) 15 January 2020, and the results were fused together for further screening.

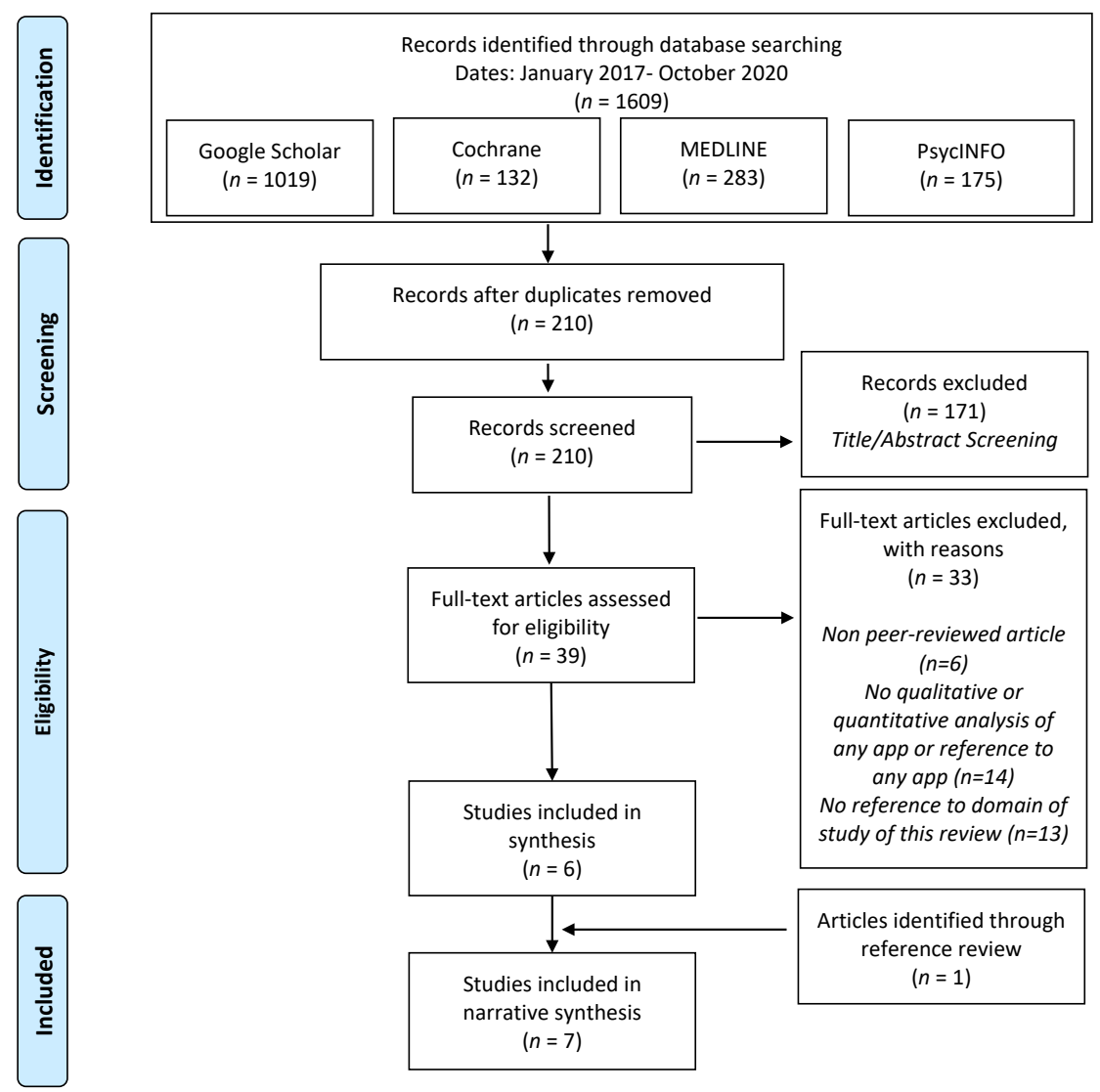

Figure 1. Prisma Workflow for Review.

Following criteria were adopted for literature identification:

Sources: Primarily, specialized literature database sources like the Cochrane Central Register of Controlled Trials database, MEDLINE, and PsycINFO were searched. Secondarily, Google Scholar was also searched for identification of relevant sources. Since, in recent years, almost all the articles are indexed in Google Scholar, and since it provides wider coverage and better recall, Google Scholar was also considered in addition to specialized electronic database sources.

Keywords: tinnitus AND (smartphone OR mobile) AND (Apps OR applications)

Search Duration: To ensure inclusion of most recent articles, the search was limited between the dates of January 2017 and October 2020.

Inclusion/Exclusion Strategy: primarily, manual screening and investigation of manuscript title and abstract, secondarily, full-text assessment.

Inclusion criteria: (1) manuscripts with English language, (2) published in peer-reviewed scientific journal, (3) manuscript clearly addressing the subject matters of tinnitus, CBT, or self-help. 
Exclusion criteria: (1) non-peer reviewed articles, (2) no qualitative or quantitative analysis of any tinnitus smartphone app, (3) manuscripts reporting on technical details about development of the app, but with missing clinical evaluation.

Intervention: Studies concerning smartphone-delivered sound therapy, or CBT for treatment and management of tinnitus were eligible. Therefore, the interventions were smartphone or mobile health apps targetting tinnitus or accompanying conditions.

Population: Patients suffering from tinnitus along-with healthcare professionals are the primary population. Secondarily, people suffering from stress, anxiety, and depression (commonly occurring comorbidities with tinnitus), as well as the healthcare professionals were also considered.

Outcomes: The main outcome of interest for this review is improvement and relief from tinnitus symptoms and accompanying conditions. Therefore, effectiveness of smartphone apps for treatment and management of tinnitus was the target outcome.

Study Designs: Mixed method studies aimed to evaluate effectiveness of smartphone apps for tinnitus treatment and management were acceptable and eligible study designs. Pilot studies were also included.

From Figure 1, after removal of duplicates, $n=210$ records were identified in the identification phase. Next, the titles and abstracts screening of these 210 selected records for eligibility resulted in the feasibility of $n=39$ records for further evaluation. The full-texts of the selected 39 records were then assessed for further suitability, resulting in a rejection of additional 32 records, due to several reasons: 5 out of the 32 records were not subjected to a peer-review process, 14 records did not perform any qualitative or quantitative analysis of the respective app, or did not reference any app and 13 records did not show any meaningful overlap with the content, aim and scope of this review. The review selection process yielded a total of $n=6$ records, whereas 1 additional article was added through a manual review of references, the total number of included records was therefore $n=7$.

In an additional step, we opted to search for relevant literature in aforementioned literature databases using app names. For this process, primarily, we performed an open keyword search on two of the most prominent app markets, namely Google's Play Store and Apple's App Store to cover both major mobile platforms (i.e., Android and iOS). We used the keywords tinnitus, hearing, noise, CBT, self-help to search the apps. After carefully screening of app titles as well as app description available on the respective app stores, the search yielded a total of 36 valid tinnitus apps. Secondarily, we performed searches on three independent third-party mHealth app libraries that are: (1) government funded National Health Service (NHS) Apps Library (https: / / www.nhs.uk/apps-library / Accessed: 15 January 2020), (2) privately funded AppScript (https:/ / www.appscript.net/ Accessed: 15 January 2020), and (3) privately funded MyHealthApps MyHealthApps (http:/ / myhealthapps.net/ Accessed: 15 January 2020). These third-party mHealth app libraries are inherently web-portals targeted towards enlisting curated smartphone apps [39]. This ancillary search of smartphone apps on third-party mHealth app libraries resulted in identification of additional 6 new apps. Finally, a total of 37 valid tinnitus apps were identified. The names of the identified apps were then used to cross-search any additional study on all previously mentioned scientific literature sources. The overall process did not yield any new literature study, and therefore, the total number of records reviewed in this article remain $n=7$.

\section{Quality Assessment}

The overall quality of each individual included study was assessed using the RoB 2: A revised Cochrane risk-of-bias tool for randomized trials [40]. The Cochrane risk of bias assessment is a valid method for quality assessment for the randomized trials [41]. The tool allows assessment of overall bias as well as biases across following 5 domains: 
D1: Bias arising from the randomization process

D2: Bias due to deviations from intended interventions

D3: Bias due to missing outcome data

D4: Bias in measurement of the outcome

D5: Bias in selection of the reported result

Each aforementioned risk of bias domain was classified as 'High', 'Some concerns', 'Low', and 'No Information'.

\section{Results}

The list of commercially available apps for tinnitus in Google's Play Store and Apple's App Store, searched through respective app market places and independent third-party mHealth app libraries are given in Table 1 (Sound Therapy and Tinnitus Management) and Table 2 (CBT). Both Tables 1 and 2 provide the app name, a small description of the app, as well as the availability on the two major platforms (i.e., Android or iOS). An asterisk $\left(^{*}\right)$ in front of the app name corresponds to the app name being reported in the literature without any clinical validation, for instance, technical description about the app development, while apps that are evidence based, reported in literature with clinical evaluation, and reviewed in this article are marked with a dagger $(\dagger)$.

Table 1. Apps providing tinnitus-related relief using sound therapy (Retrieved: 15 January 2020).

\begin{tabular}{llr}
\hline App Name & Description & Platform \\
\hline Audio Notch *+ & $\begin{array}{l}\text { Allows creation \& listening to customized Notched } \\
\text { Sound Therapy }\end{array}$ & Android, iOS \\
\hline H \& T Sound Therapy & $\begin{array}{l}\text { Noise Player (pink noise, white noise or brown } \\
\text { noise) for masking tinnitus }\end{array}$ & Android \\
\hline Kalmeda mynoise * & Offers medically-based, individual tinnitus therapy & Android, iOS \\
\hline myNoise * & $\begin{array}{l}\text { Controlling tinnitus via combination of different } \\
\text { sounds and noises }\end{array}$ & Android, iOS \\
\hline Relax Noise 3* & Masking tinnitus by using red, white, or pink noise & Android \\
\hline SimplyNoise * & $\begin{array}{l}\text { Controlling and managing stress and tinnitus using white, } \\
\text { and brown noises }\end{array}$ & Android, iOS \\
\hline Starkey Relax * & Tinnitus masking, self-management, and education app & Android, iOS \\
\hline StopTinnitus * & Masking tinnitus using customised tones & Android, iOS \\
\hline Tinnitus Aid & $\begin{array}{l}\text { Management of tinnitus symptoms by sound therapy } \\
\text { specific to tinnitus frequencies }\end{array}$ & iOS \\
\hline Tinnitracks * & $\begin{array}{l}\text { Controlling and managing tinnitus by filtering out music } \\
\text { for sound therapy }\end{array}$ & Android, iOS \\
\hline Tinnitus Balance App * & Controlling tinnitus using customized sounds or music & Android, iOS \\
\hline Tinnitus Help * & Tinnitus masking using natural sounds or music & Android, iOS \\
\hline Tinnitus Notch & Provided custom tailored notch therapy for tinnitus relief \\
\hline Tinnitus Peace & $\begin{array}{l}\text { Offers melodies to match the frequency of tinnitus to } \\
\text { reduce its effects }\end{array}$ & Android \\
\hline Tinnitus masking using different sound techniques & Android \\
\hline
\end{tabular}


Table 1. Cont.

\begin{tabular}{llr}
\hline App Name & Description & Platform \\
\hline Tinnitus Relief * & $\begin{array}{l}\text { Controlling tinnitus using information on } \\
\text { different relaxation exercises }\end{array}$ & Android \\
\hline Tinnitus Sound Therapy & Sound/Acoustic therapy for masking tinnitus & Android \\
\hline Tinnitus Tailor * & Personalized sound therapy with sounds created using AI. & Android, iOS \\
\hline Tinnitus Therapy (Lite) ${ }^{*+}$ & Avoiding tinnitus with sound masking and therapy & Android, iOS \\
\hline Tonal Tinnitus Therapy * & $\begin{array}{l}\text { Helps to mitigate symptoms of tonal tinnitus based on } \\
\text { acoustic neuromodulation }\end{array}$ & Android \\
\hline Whist* & $\begin{array}{l}\text { Controlling tinnitus using sounds with adjusted volume, } \\
\text { pitch etc. }\end{array}$ & Android, iOS \\
\hline White Noise (Lite) ${ }^{*}$ & Masking tinnitus using environmental sounds & Android, iOS \\
\hline Widex Zen * & $\begin{array}{l}\text { Avoiding tinnitus using relaxing zen sounds, } \\
\text { and exercises to manage tinnitus }\end{array}$ & Android, iOS \\
\hline
\end{tabular}

An arbitrary categorical distribution of the 36 identified commercially available smartphone apps with 2 major categories and types is depicted in Figure 2. Based on the app title and description in the app store, we identified 2 main categories: (1) Sound Therapy (23 apps), and (2) CBT (13 apps). In the 'Sound Therapy' main category, 7 apps offered tinnitus masking, while 5 apps offered tinnitus habituation (habituation is the process of gradually enabling tinnitus sufferers' to find ways to emotionally and psychologically cope with tinnitus sounds to find relief). Similarly, 4 apps provided acoustic neuromodulation, 4 apps offered distraction from tinnitus using customized sounds, 2 apps delivered notched therapy for tinnitus relief, and 1 app used zen sounds to offer relief from tinnitus. 'CBT' apps for tinnitus made up the second main category, in which 7 apps provided CBT self-help, 3 apps were CBT chatbots, 2 apps offered CBT-Acceptance and Commitment Therapy (ACT), and 1 app used Visual CBT for tinnitus relief.

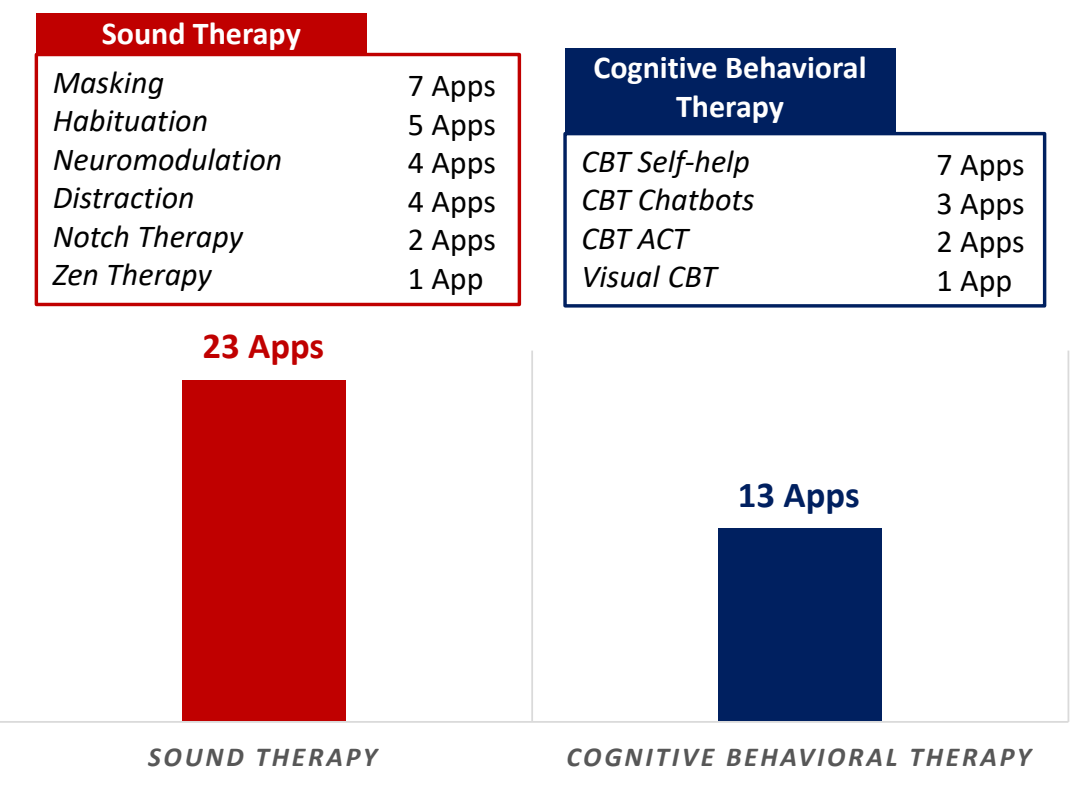

Figure 2. App Types and Categories. 
The initial screening of 210 articles and full-text assessment of 39 articles yielded a total of 7 articles that fulfilled the review criteria and were included in the analysis. All 7 scientific studies are profiled and delineated in Table 3, along-with the characteristics of the study, and the strategy adopted to validate the smartphone app. Furthermore, Table 3 reports on the final outcomes and results of the study. All 7 studies reviewed in this article reported the qualitative analysis using questionnaires like the Tinnitus Handicap Inventory (THI) [42], Tinnitus Functional Index (TFI) [43], Patient Health Questionnaire (PHQ) [44], or ratings scales such as Generalized Anxiety Disorder Scale (GAD-7) [45]. The quantitative analyses results are reported using Latent Dirichlet Allocation (LDA) model [46], or Statistical Package for the Social Sciences (SPSS) program [47]. None of the scientific studies included in this review reported on any side or adverse effect related to smartphone-delivered treatments.

Table 2. Apps providing tinnitus-related relief using Cognitive Behavioral Therapy (CBT) (Retrieved: 15 January 2020).

\begin{tabular}{lll}
\hline App Name & Description & Platform \\
\hline Beltone Tinnitus Calmer & $\begin{array}{l}\text { Combination of relaxation exercise and sound therapy } \\
\text { to avoid tinnitus }\end{array}$ & Android, iOS \\
\hline CBT Companion & Employs visual tools to learn \& practice CBT techniques & Android, iOS \\
\hline Diapason for tinnitus * & Game-based digital therapy app for tinnitus relief & Android, iOS \\
\hline MindShift CBT *+ & CBT tools to manage and control anxiety & Android, iOS \\
\hline Moodfit-Stress \& Anxiety & $\begin{array}{l}\text { Stress \& Anxiety management and tracking, } \\
\text { offers CBT exercises for relief }\end{array}$ & Android \\
\hline Quirk CBT & Self-help CBT app based on 'three column technique' & Android, iOS \\
\hline ReSound Relief * + & $\begin{array}{l}\text { Avoiding tinnitus using combination of sound therapy } \\
\text { and relaxation exercise }\end{array}$ & Android, iOS \\
\hline Sanvello-Stress \& Anxiety & Audio \& Video CBT exercises for anxiety management & Android, iOS \\
\hline Stress \& Anxiety Companion & CBT based visual exercises to manage stress and anxiety & Android, iOS \\
\hline What's Up? & $\begin{array}{l}\text { Offers CBT \& ACT methods to manage stress, anxiety } \\
\text { as well as depression }\end{array}$ & Android, iOS \\
\hline W Mental Health App & A chatbot for guided CBT to manage stress and anxiety & Android, iOS \\
\hline Wysa * ++ & A chatbot offering CBT and DBT techniques & Android, iOS \\
\hline Youper: Emotional Health * & $\begin{array}{l}\text { A chatbot based on CBT and ACT techniques, } \\
\text { monitoring and tracking mood changes }\end{array}$ & Android, iOS \\
\hline
\end{tabular}

Table 3. Identified scientific studies delineated.

\begin{tabular}{|c|c|c|c|}
\hline \multicolumn{4}{|c|}{ Study } \\
\hline App/Period & Characteristics & Strategy & Outcome \& Results \\
\hline \multicolumn{4}{|c|}{ Sabarish and Kruthika [48] } \\
\hline $\begin{array}{l}\text { Tinnitus Therapy Lite } \\
45 \text { min usage for } \\
1 \text { month }\end{array}$ & $\begin{array}{l}\text { Clinical evaluation report } \\
\text { Convenience sampling } \\
5 \text { patients: } 25-35 \text { yo. } \\
3 \text { phases study: } \\
\text { Phase I: Audiological evaluations. } \\
\text { Phase II: Tinnitus evaluation. } \\
\text { Phase III: THI and app evaluations. }\end{array}$ & $\begin{array}{l}\text { Check app effectiveness by checking THI } \\
\text { score changes before \& after app usage. } \\
\text { Patients trained to use app. } \\
\text { Clinical evaluation \& regular follow-ups. }\end{array}$ & $\begin{array}{l}\text { Outcome: Tinnitus } \\
\text { THI scale improved by } 1 \text { grade or } 18 \text { points. } \\
\text { Tinnitus severity dropped by } 25-30 \% \text {. } \\
\text { Users reported satisfaction in app usage. } \\
\text { App provided tinnitus pitch and loudness } \\
\text { understanding. } \\
\text { Low number of participants make the results } \\
\text { statistically insignificant. }\end{array}$ \\
\hline
\end{tabular}


Table 3. Cont.

\begin{tabular}{|c|c|c|c|}
\hline \multicolumn{4}{|c|}{ Study } \\
\hline App/Period & Characteristics & Strategy & Outcome \& Results \\
\hline \multicolumn{4}{|c|}{ Tyler et al. [49] } \\
\hline $\begin{array}{l}\text { ReSound Relief } \\
2 \text { weeks }\end{array}$ & $\begin{array}{l}\text { Clinical evaluation report } \\
\text { Convenience sampling } \\
16 \text { Participants: } 36-85 \text { yo. } \\
3 \text { non-tinnitus participants. } \\
\text { Tested with Apple's 6th Gen. iPod, } \\
\text { streaming to Cochlear Implant (CI) } \\
\text { device. } \\
\text { Laboratory Trial: } 13 \text { participants. } \\
\text { Home Trial: } 10 \text { Participants. }\end{array}$ & $\begin{array}{l}\text { Validate the app sounds and pre-trial } \\
\text { \& post-trial tinnitus on a scale of } 0-100 \\
\text { for Cochlear implant users. } \\
\text { Laboratory Trial: } 5 \text { mins } \\
\text { Home Trial: 2-weeks } \\
\text { Home Trial participants reported tinnitus } \\
\text { loudness and overall effectiveness of } \\
\text { sound therapy using a scale from } 0-100 \\
\text { via online questionnaires. }\end{array}$ & $\begin{array}{l}\text { Outcome: Tinnitus } \\
\text { Laboratory trial participants reported sounds } \\
\text { of rain, music \& waves as acceptable. } \\
\text { Home trial participants reported sounds of } \\
\text { insects \& pink noise as acceptable. } \\
\text { Both groups reported lower post-trial tinnitus. } \\
3 / 10 \text { home trial participants found the app } \\
\text { more than or equal to } 70 \% \text { effective. }\end{array}$ \\
\hline \multicolumn{4}{|c|}{ Kim et al. [50] } \\
\hline $\begin{array}{l}\text { Audio Notch } \\
13 \text { March-15 March } \\
30-60 \text { min } \\
\text { app usage. } \\
\text { Ginkgo Biloba } \\
\text { treatment: } \\
3 \text { months }\end{array}$ & $\begin{array}{l}\text { Pilot study } \\
\text { Random sampling } \\
26 \text { patients, THI }>=18 \text {. } \\
\text { Ages: } 20-65 \text { yo. } \\
\text { Specific inclusion criteria. } \\
\text { Participants were instructed on how } \\
\text { to use the app. }\end{array}$ & $\begin{array}{l}\text { Check for THI improvements. } \\
\text { Distress, Depressive mood, } \\
\text { \& Audiograms were measured prior } \\
\text { to the study. }\end{array}$ & $\begin{array}{l}\text { Outcome: Tinnitus } \\
\text { Emotional score of THI improved by } \\
11 \text { points. } \\
\text { App reported to be effective if patient had } \\
\text { higher initial THI. } \\
\text { Listening to familiar music gives emotional } \\
\text { comfort and eases distress }\end{array}$ \\
\hline \multicolumn{4}{|c|}{ Inkster et al. [51] } \\
\hline $\begin{array}{l}\text { Wysa } \\
17 \text { July-17 September }\end{array}$ & $\begin{array}{l}\text { Mixed methods study } \\
\text { Random sampling } \\
129 \text { patients. } \\
\text { Only patients with Patient } \\
\text { Health Questionnaire (PHQ) } \\
\text { depression score }>6 \text {. }\end{array}$ & $\begin{array}{l}\text { Test for app effectiveness focusing on } \\
\text { psychological and mental wellness. } \\
\text { Compare score difference for high and low } \\
\text { usage groups between Pre-PHQ-9 } \\
\text { \& Post-PHQ-9. } \\
\text { Engagement effectiveness using } \\
\text { thematic analysis. } \\
\text { Mann-Whitney U test for usage } \\
\text { effectiveness impact between usage groups. }\end{array}$ & $\begin{array}{l}\text { Outcome: Depression } \\
\text { App gives personalised feedback with good } \\
\text { experience and is reported as a bit of hard } \\
\text { coping with it. } \\
\text { Both groups had reduction in PHQ-9 scores. } \\
\text { App classified objections with a recall of } 62.1 \% \text {. } \\
\text { Users with high usage had better improvements } \\
\text { PHQ-2 also lowered proving that the app } \\
\text { is effective for patients with severe symptoms } \\
\text { of depression. }\end{array}$ \\
\hline \multicolumn{4}{|c|}{ Fitzpatrick et al. [52] } \\
\hline $\begin{array}{l}\text { Woebot } \\
\text { 17 January-17 February: } \\
\text { 2-Weeks }\end{array}$ & $\begin{array}{l}\text { Randomized Controlled Trial } \\
\text { Random sampling } \\
70 \text { patients. } \\
\text { Avg. age: } 22.20 \text { yo. } \\
34 \text { college students } \\
\text { using the app. } \\
36 \text { reading only the CBT } \\
\text { related book. }\end{array}$ & $\begin{array}{l}\text { Tested as an alternative CBT } \\
\text { delivery method. } \\
\text { Test for prediction of depression severity } \\
\text { using PHQ-9, (Generalized Anxiety } \\
\text { Disorder) GAD-7, \& Positive and Negative } \\
\text { Affect Scale. }\end{array}$ & $\begin{array}{l}\text { Outcome: Anxiety \& depression } \\
\text { Depression scores of users using the app } \\
\text { decreased significantly in comparison to } \\
\text { book users. } \\
\text { Both groups had lower GAD-7 scores. }\end{array}$ \\
\hline \multicolumn{4}{|c|}{ Paul and Fleming [53] } \\
\hline $\begin{array}{l}\text { MindShift } \\
3 \text { weeks } \\
5 \text { days / week } \\
\text { Minimum } 15 \text { min } \\
\text { per day usage }\end{array}$ & $\begin{array}{l}\text { Exploratory Study } \\
\text { Stratified sampling } \\
104 \text { students: } \\
\text { Avg. age } 19.83 \text { yo. } \\
\text { Selection based on high } \\
\text { levels of anxiety seen in } \\
\text { PHQ scores. }\end{array}$ & $\begin{array}{l}\text { Test for reductions in anxiety, depression } \\
\text { from baseline PHQ-15, GAD-7, and PHQ-9 } \\
\text { scores and app acceptance. } \\
\text { Check for users feedback via } 3 \text { questions } \\
\text { about usability and acceptability. }\end{array}$ & $\begin{array}{l}\text { Outcome: Anxiety and depression } \\
\text { Reduction in anxiety after } 3 \text { weeks } \\
\text { usage reported. } \\
\text { Users reported satisfaction in app usability } \\
\text { and acceptability. }\end{array}$ \\
\hline \multicolumn{4}{|c|}{ Henry et al. [54] } \\
\hline $\begin{array}{l}\text { Tinnitus Coach } \\
6-8 \text { weeks }\end{array}$ & $\begin{array}{l}\text { Observational field study } \\
\text { Stratified sampling } \\
25 \text { participants } \\
\text { Every participant received phones } \\
\text { with pre-loaded app. } \\
\text { Monetary incentives offered. }\end{array}$ & $\begin{array}{l}\text { Test app in a 3-phase study: } \\
\text { 1. Design } \mathcal{E} \text { Develop, } \\
\text { 2. Initial Test, } \\
\text { 3. Evaluate. } \\
\text { Measure Tinnitus Questionnaire and the } \\
\text { Tinnitus Functional Index (TFI) after } \\
\text { app usage. }\end{array}$ & $\begin{array}{l}\text { Outcome: Tinnitus } \\
\text { Insignificant or minor TFI changes were } \\
\text { reported, where only } 8 \text { participants reported } \\
\text { reduced TFI. } \\
\text { Users suggested that coping skills taught as } \\
\text { part of Progressive Tinnitus Management } \\
\text { improved quality of life with tinnitus. }\end{array}$ \\
\hline
\end{tabular}

In terms of sound-related therapies for tinnitus management and treatment, Table 3 presents three studies [48-50] on the effectiveness of three apps (Tinnitus Therapy Lite, ReSound Relief, Audio Notch). Among these, we can note that there is only one study with appropriate number of patients to be considered to provide significant results [50]. The study presented in Kim et at. [50] employs the use of a smartphone app to deliver tailor-made notched music to tinnitus patients, resulting in improvement of overall THI scores (emotional score of THI in particular) of tinnitus patients. From Kim et al. [50], as Ginkgo Biloba was administered complimentary in combination with tailor-made notched music therapy, it is hard to determine the stand-alone effectiveness of either of the treatment. Regardless of having lower number of 
patients, the studies presented in Sabarish and Kruthika [48] and ,Tyler et al. [49] do report on reducing the tinnitus-related distress after receiving sound therapy. Tyler et al. [49] aims at understanding the effects of delivering sound therapy using the Resound Relief (updated to Resound Tinnitus Relief) app to cochlear implant patients. The results show that $3 / 10$ home trial participants rated the app and sound therapy in reducing tinnitus with high (70\%) effectiveness, another $3 / 10$ participants reported the app with moderate (20-40\%) effectiveness, another 3/10 participant rated the app with low (0-20\%) effectiveness, while $1 / 10$ patients found the app to be completely ineffective.

Furthermore, Table 3 presents three studies [51-53] on the effectiveness of three different CBT apps (Wysa, Woebot, MindShift). In terms of depression, the Wysa app showed promising results in reducing depression in patients with severe symptoms with continuous usage of the app. Reduction in PHQ (PHQ-9 and PHQ-2) scores were reported by the patients after usage of the Wysa app [51]. The Woebot app showed significant reduction of depression scores in comparison to patients using the CBT book [52]. In terms of anxiety, the MindShift app reduced anxiety in students after 3 weeks of usage, where the app was found to be satisfactory in terms of usability and acceptability [53].

Finally, Henry et al. [54] reports on the effectiveness of the Tinnitus Coach smartphone app offering the coping skills education program of the Progressive Tinnitus Management (PTM). Henry et al. [54] reports that $8 / 25$ study participants had reduced TFI scores, an indication that the app was beneficial in moderately reducing tinnitus symptoms. Although the participants found most of the content of the app favorable, some features of the app were found to be too complex. Nevertheless, most of the app users suggested that their quality of life improved due to the coping skills taught as part of PTM program. Herein, please note that the Tinnitus Coach smartphone app is not commercially available on either Google's Play Store or Apple's App Store.

The Figure 3 shows the results of risk of bias assessment for individual studies with the help of a traffic light plot, while the summary plot for risk of bias assessment results is depicted in Figure 4. Both plots were generated using the robvis tool [55]. Based on the outcomes of the over-all assessment (Figure 3), only 2 out of 7 studies [51,52] had 'Some concerns' of bias, while the rest of the 5 studies had 'High risk' of bias. Please note that since it is almost impossible to conceal the type of intervention from patients and healthcare providers in case of mhealth interventions, the domain 'D2: Biases due to deviations from intended interventions' was assessed at 'Low risk' for all identified studies (Figure 4).

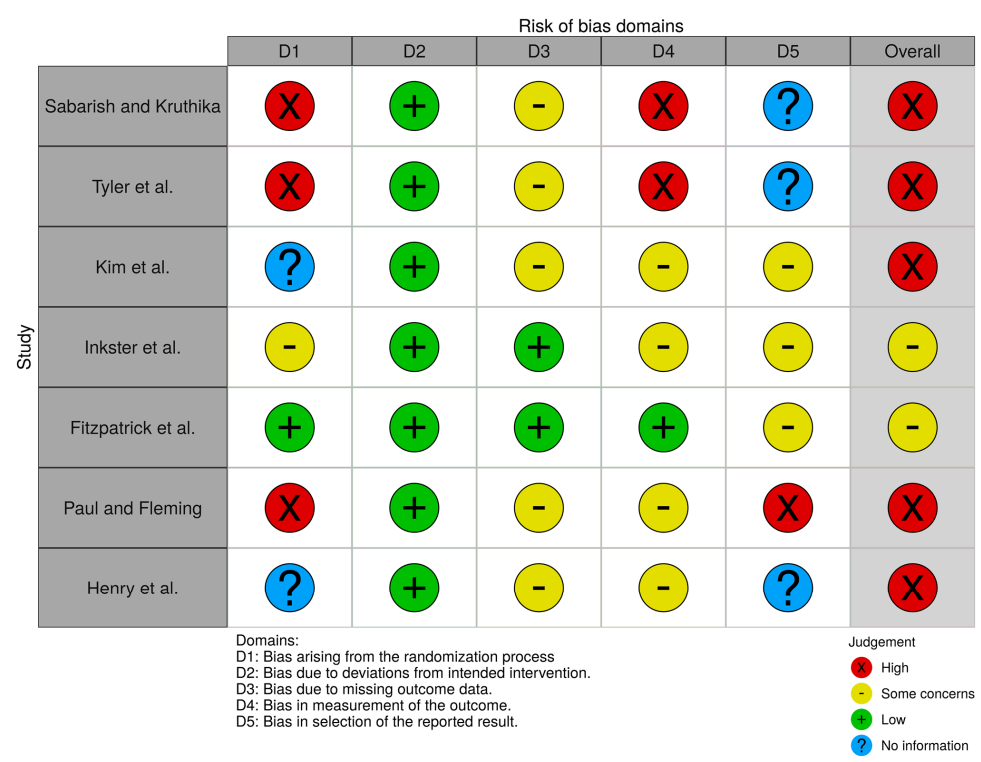

Figure 3. Risk of Bias Assessment-Traffic Light Plot [55]. 


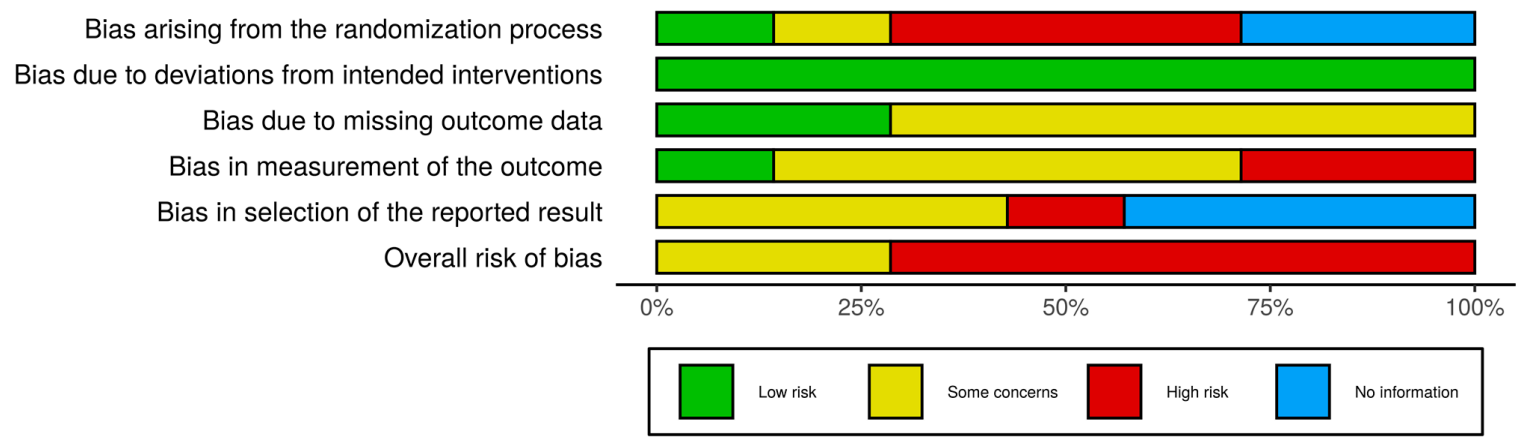

Figure 4. Risk of Bias Assessment—Summary Plot [55].

\section{Discussions}

The aim of this study was to review scientific studies reporting on effectiveness of smartphone apps used for the management and treatment of tinnitus. The literature identification process resulted in inclusion of 7 scientific studies, for which Table 3 shows the outcome of the included studies. Albeit smartphone apps for tinnitus have been around and available on different platforms for a long time, the amount of research to validate the apps as well as to evaluate the clinical effectiveness of the apps is limited. In our analysis of the identified scientific literature, only three clinical scientific studies pertaining to tinnitus-related therapies, four scientific studies related to CBT therapies were found. From our review of existing literature, we determined that most of the studies with regards to smartphone apps either report on the development, design, implementation, or adoption of smartphone apps in the context of tinnitus. We believe that there is still need of research to be done to clinically evaluate and validate the effectiveness of smartphone apps for tinnitus treatment and management.

Smartphone technology offers a large variety of functions that can be used for the clinical interventions and diagnosis in the chronic tinnitus. For instance, smartphone apps can be used to provide structured counseling to the patients via textual, auditory stimulation using notched music interventions [56] or video information and practical tips. Tailor-made notched music therapy has proven to be an effective treatment modality in reducing tinnitus-related loudness and auditory cortex activity, specifically, while administered for a longer time duration [56,57]. For the diagnosis of tinnitus, Ecological Momentary Assessment (EMA) approaches have been used by several groups to analyze the dynamic changes of the tinnitus symptoms [58].

Different treatment modalities for management of tinnitus symptoms exist, for instance, tinnitus retaining and sound therapy, tinnitus masking, conventional drug delivery, and even brain stimulation-among them, tinnitus retaining therapy, tinnitus masking, or sound therapy using sound generators and CBT as counseling, are standard treatment procedures [1]. Most of the tinnitus relief apps that are generally published on app markets offer tinnitus masking, or sound therapies using different sound techniques like acoustic neuromodulation, notched sound, or amplitude modulation. Importantly, it is significant to note that the smartphones are capable of delivering acoustic and sound therapy reliably and accurately [59].

In addition to sound and tinnitus therapies, CBT has been pivotal for the treatment of tinnitus [60]. It is argued that CBT has no effect on the acoustic characteristics of tinnitus, such as subjective loudness of tinnitus [61,62]. CBT has proven to be effective in improving the overall quality of life of tinnitus patients and reducing symptoms of tinnitus-related psychological comorbidities, such as depression and anxiety [61,63]. Besides CBT being administered face to face with a CBT clinician, it can also be administered via the internet or smartphone as self-help treatment for tinnitus [64]. Evidence from the literature suggests that internet-delivered self-help tinnitus treatment shows positive results and it is an 
effective treatment modality $[65,66]$. Consequently, the smartphone app markets have a variety of apps that are specifically designed for CBT for tinnitus, such as Beltone Tinnitus Calmer, Diapason for Tinnitus, ReSound Relief.

Besides, sound therapy and CBT, Progressive Tinnitus Management (PTM) program has recently gained momentum as a possible alternative method for tinnitus treatment and management [67]. PTM is a multi-leveled interdisciplinary care program involving audiologists and mental health providers to offer tinnitus management $[67,68]$. Level-3 of PTM program serves as an educational program to teach tinnitus sufferers different coping skills for self-management of tinnitus-related distress [69]. It also includes education about different sound therapies taught by audiologists, and delivery of CBT by mental health providers. A randomized control trial showed that coping skills taught as part of the PTM are effective in reducing tinnitus-related distress [70]. The coping skills education program of the PTM can be carried out remotely using videoconferencing [67] and smartphones [54].

Based on the findings of this review and in our opinion, all three studies [48-50] providing sound-related therapies for tinnitus management and treatment (Table 3) have predominantly positive findings in relation to tinnitus treatment and management, an indication that smartphone-delivered sound therapy apps can have positive impact on reducing tinnitus-related distress in patients suffering from tinnitus. However, it is also notable that only 3 out of 23 identified commercially available apps (Table 1) providing sound therapy for tinnitus relief have been so far validated, thus prompting the need for further research.

Similarly, three studies [51-53] validating the effectiveness of CBT apps (Table 3) reported no direct results in relation to tinnitus treatment or management, instead, the primary focus was on anxiety and depression. However, the limited number of found studies evaluating CBT apps have a notable number of positive results, thus indicating that app-based CBT interventions can definitely help patients to cope with their depression and anxiety problems. Despite the fact that the effectiveness of CBT is well-documented and established for several anxiety disorders [34], additional research is further recommended to understand the effectiveness of CBT in tinnitus related depression and anxiety [61]. Although, the current evidence suggests that internet or smartphone delivered CBT treatment for tinnitus is an effective modality $[60,66]$, from the presented literature review, we establish that studies related to validating the effectiveness of smartphone-delivered or app-based CBT treatment, specifically for tinnitus, are critically not well represented.

Overall, the knowledge about the effectiveness of mobile and smartphone apps in mitigating tinnitus symptoms is very limited and is at its early stage. On one hand, our review process identified that there is a plethora of smartphone apps for tinnitus treatment and management, and obviously the interest to develop and publish new apps will certainly increase, however, the research to clinically validate the smartphone apps is very limited. On other hand, from the limited number of studies included in review, it can be safely concluded that the current clinical role of smartphone apps for tinnitus treatment and management appears promising. Care should be practiced in interpreting the findings of this review, further, the following limitations should be considered. There was a significant risk of bias for all included studies across all domains. There were very limited studies, among which only 4 out of 7 specifically targeted the tinnitus outcome. Finally, the studies included in studies ranged from observational studies, pilot studies, mixed-method studies, all the way to RCTs, although, this allows an exhaustive inclusion of contemporary findings, at the same time it can also influence the over-all synthesis of the results of the review. 


\section{Conclusions}

The review presented in this paper thoroughly attempted to highlight the impact of smartphone and mobile health applications, specifically within the context of tinnitus research. Our review approach used the PRISMA guidelines to identify and select the relevant scientific studies. In order to ensure inclusion of relevant literature, we performed searches on market places of prominent mobile platforms (iOS and Android) and the three independent third-party mHealth app libraries to find commercially available smartphone apps for tinnitus. The app names were thus used to find additional literature. Overall, 7 scientific studies validating 7 smartphone apps were identified and reviewed. Based on this, through these measures we were able to (1) comprehensively capture the wide array of heterogeneous apps utilized in tinnitus management and treatment and (2) review and highlight the clinical effectiveness of smartphone-delivered tinnitus management and treatment.

Limitations-We understand the limited coverage of keyword-based search as there might be additional relevant documents not matching the chosen keywords. We addressed this issue by isolating keywords that caused reduced recall, however, we still believe that it can be further improved. Furthermore, we thoroughly ensured the selection of relevant literature based on primarily investigating the abstract and introduction for relevance, and secondarily based on the content of the paper. Again, we understand that this approach is subjective and highly relies on the knowledge of the inspector about the domain and can be further improved by collecting opinions from additional domain experts. During our searches, we identified apps, which were relevant for this review and were part of Google's PlayStore or Apple's AppStore at one point in time, however, they were removed from respective app stores due to policy conformation issues. Usually, removal of an app from these app stores is properly justified, however, these restrictions can sometimes be inconsistent.

For future work, we primarily aim to extend our work by reviewing internet- and computer-based behavioural therapies applied directly in the context of tinnitus research. Herein, an additional focus would be to include studies that report on use of auxiliary and peripheral sensors in assisting therapeutical solutions. For instance, the use of smartwatches or wristbands to acquire physiological attributes of patients suffering from tinnitus could be additionally included. Furthermore, we aim to employ app evaluation and assessment instruments like Mobile Application Ratings Scale (MARS) [71] and the THESIS app evaluation instrument [72] to study the objective quality of the smartphone apps.

Author Contributions: M.M. undertook the database searches, cataloguing, conception, draft, and revision of the paper. A.D. helped in writing and reviewing Section 4. R.P., W.S., and M.R. helped by critically revising the manuscript. F.J.H. contributed by helping in writing Section 1, critical revisions, and final approval of the manuscript, as well as supervision of the entire review. All authors have read and agreed to the published version of the manuscript.

Funding: This publication is a result of research supported by funding from the European Union's Horizon 2020 research and innovation programme under the Marie Skłodowska-Curie grant agreement number 722064 (European School for Interdisciplinary Tinnitus Research, ESIT) [73].

Conflicts of Interest: The authors declare no conflict of interest.

\section{References}

1. Baguley, D.; McFerran, D.; Hall, D. Tinnitus. Lancet 2013, 382, 1600-1607. [CrossRef]

2. Mazurek, B.; Szczepek, A.; Hebert, S. Stress and tinnitus. HNO 2015, 63, 258-265. [CrossRef] [PubMed]

3. Jastreboff, P.J.; Jastreboff, M.M. Tinnitus retraining therapy (TRT) as a method for treatment of tinnitus and hyperacusis patients. J. Am. Acad. Audiol. 2000, 11, 162-177. [PubMed]

4. Probst, T.; Pryss, R.; Langguth, B.; Schlee, W. Emotion dynamics and tinnitus: daily life data from the “TrackYourTinnitus" application. Sci. Rep. 2016, 6, 31166. [CrossRef] [PubMed] 
5. Schlee, W.; Schecklmann, M.; Lehner, A.; Kreuzer, P.M.; Vielsmeier, V.; Poeppl, T.B.; Langguth, B. Reduced variability of auditory alpha activity in chronic tinnitus. Neural Plast. 2014, 2014. [CrossRef] [PubMed]

6. Probst, T.; Pryss, R.C.; Langguth, B.; Rauschecker, J.P.; Schobel, J.; Reichert, M.; Spiliopoulou, M.; Schlee, W.; Zimmermann, J. Does tinnitus depend on time-of-day? An ecological momentary assessment study with the TrackYourTinnitus application. Front. Aging Neurosci. 2017, 9, 253. [CrossRef]

7. Kimoto, K.; Aiba, S.; Takashima, R.; Suzuki, K.; Takekawa, H.; Watanabe, Y.; Tatsumoto, M.; Hirata, K. Influence of barometric pressure in patients with migraine headache. Intern. Med. 2011, 50, 1923-1928. [CrossRef]

8. Schmidt, W.; Sarran, C.; Ronan, N.; Barrett, G.; Whinney, D.J.; Fleming, L.E.; Osborne, N.J.; Tyrrell, J. The weather and Meniere's disease: a longitudinal analysis in the UK. Otol. Neurotol. 2017, 38, 225. [CrossRef]

9. Schlee, W.; Pryss, R.C.; Probst, T.; Schobel, J.; Bachmeier, A.; Reichert, M.; Langguth, B. Measuring the moment-to-moment variability of tinnitus: the TrackYourTinnitus smart phone app. Front. Aging Neurosci. 2016, 8, 294. [CrossRef]

10. Mehdi, M. Smart mobile crowdsensing for tinnitus research: student research abstract. In Proceedings of the 34th ACM/SIGAPP Symposium on Applied Computing; ACM: New York, NY, USA, 2019; pp. 1220-1223.

11. Mehdi, M.; Schwager, D.; Pryss, R.; Schlee, W.; Reichert, M.; Hauck, F.J. Towards Automated Smart Mobile Crowdsensing for Tinnitus Research. In 32nd IEEE CBMS International Symposium on Computer-Based Medical Systems; IEEE: New York, NY, USA, 2019.

12. Kuhn, E.; Greene, C.; Hoffman, J.; Nguyen, T.; Wald, L.; Schmidt, J.; Ramsey, K.M.; Ruzek, J. Preliminary evaluation of PTSD Coach, a smartphone app for post-traumatic stress symptoms. Mil. Med. 2014, 179, 12-18. [CrossRef]

13. Kuhn, E.; Kanuri, N.; Hoffman, J.E.; Garvert, D.W.; Ruzek, J.I.; Taylor, C.B. A randomized controlled trial of a smartphone app for posttraumatic stress disorder symptoms. J. Consult. Clin. Psychol. 2017, 85, 267. [CrossRef] [PubMed]

14. Economides, M.; Martman, J.; Bell, M.J.; Sanderson, B. Improvements in stress, affect, and irritability following brief use of a mindfulness-based smartphone app: a randomized controlled trial. Mindfulness 2018, 9, $1584-1593$. [CrossRef] [PubMed]

15. Van Ameringen, M.; Turna, J.; Khalesi, Z.; Pullia, K.; Patterson, B. There is an app for that! The current state of mobile applications (apps) for DSM-5 obsessive-compulsive disorder, posttraumatic stress disorder, anxiety and mood disorders. Depress. Anxiety 2017, 34, 526-539. [CrossRef] [PubMed]

16. Delbaere, K.; Valenzuela, T.; Woodbury, A.; Davies, T.; Yeong, J.; Steffens, D.; Miles, L.; Pickett, L.; Zijlstra, G.; Clemson, L.; et al. Evaluating the effectiveness of a home-based exercise programme delivered through a tablet computer for preventing falls in older community-dwelling people over 2 years: Study protocol for the Standing Tall randomised controlled trial. BMJ Open 2015, 5, e009173. [CrossRef]

17. Bright, T.; Pallawela, D. Validated smartphone-based apps for ear and hearing assessments: A review. JMIR Rehabil. Assist. Technol. 2016, 3, e13. [CrossRef]

18. Masalski, M.; Grysiński, T.; Kręcicki, T. Hearing tests based on biologically calibrated mobile devices: Comparison with pure-tone audiometry. JMIR mHealth uHealth 2018, 6, e10. [CrossRef]

19. Kardous, C.A.; Shaw, P.B. Evaluation of smartphone sound measurement applications. J. Acoust. Soc. Am. 2014, 135, EL186-EL192. [CrossRef]

20. Dlugaiczyk, J.; Thiemer, M.; Neubert, C.; Schorn, B.A.; Schick, B. The aVOR App Increases Medical Students' Competence in Treating Benign Paroxysmal Positional Vertigo (BPPV). Otol. Neurotol. 2018, 39, e401-e406. [CrossRef]

21. Bromwich, M.A.; Parnes, L.S. The DizzyFIX: initial results of a new dynamic visual device for the home treatment of benign paroxysmal positional vertigo. J. Otolaryngol. Head Neck Surg. 2008, 37, 3.

22. Organ, B.; Liu, H.; Bromwich, M. An iPhone-assisted particle repositioning maneuver for benign paroxysmal positional vertigo (BPPV): a prospective randomized study. J. Am. Board Fam. Med. 2015, 28, 118-120. [CrossRef]

23. Beauvais, B.S.; Rialle, V.; Sablier, J. Myvigi: An android application to detect fall and wandering. In Proceedings of the Sixth International Conference on Mobile Ubiquitous Computing, Systems, Services and Technologies; UBICOMM: San Jose, CA, USA, 2012; pp. 156-160. 
24. Sposaro, F.; Danielson, J.; Tyson, G. iWander: An Android application for dementia patients. In 2010 Annual International Conference of the IEEE Engineering in Medicine and Biology; IEEE: New York, NY, USA, 2010; pp. 3875-3878.

25. Buijink, A.W.G.; Visser, B.J.; Marshall, L. Medical apps for smartphones: Lack of evidence undermines quality and safety. BMJ Evid.-Based Med. 2013, 18, 90-92. [CrossRef] [PubMed]

26. Zhao, J.; Freeman, B.; Li, M. Can mobile phone apps influence people's health behavior change? An evidence review. J. Med. Internet Res. 2016, 18, e287. [CrossRef] [PubMed]

27. Ventola, C.L. Mobile devices and apps for health care professionals: uses and benefits. Pharm. Ther. 2014, $39,356$.

28. Naslund, J.A.; Aschbrenner, K.A.; Barre, L.K.; Bartels, S.J. Feasibility of popular m-health technologies for activity tracking among individuals with serious mental illness. Telemed. Health 2015, 21, 213-216. [CrossRef]

29. Nelson, E.C.; Verhagen, T.; Noordzij, M.L. Health empowerment through activity trackers: An empirical smart wristband study. Comput. Hum. Behav. 2016, 62, 364-374. [CrossRef]

30. Mehdi, M.; Riha, C.; Neff, P.; Dode, A.; Pryss, R.; Schlee, W.; Reichert, M.; Hauck, F.J. Smartphone Apps in the Context of Tinnitus: Systematic Review. Sensors 2020, 20, 1725. [CrossRef]

31. Mosa, A.S.M.; Yoo, I.; Sheets, L. A Systematic Review of Healthcare Applications for Smartphones. BMC Med. Inform. Decis. Mak. 2012, 12, 67. [CrossRef]

32. Lui, J.H.; Marcus, D.K.; Barry, C.T. Evidence-based apps? A review of mental health mobile applications in a psychotherapy context. Prof. Psychol. Res. Pract. 2017, 48, 199. [CrossRef]

33. Kalle, S.; Schlee, W.; Pryss, R.C.; Probst, T.; Reichert, M.; Langguth, B.; Spiliopoulou, M. Review of smart services for tinnitus self-help, diagnostics and treatments. Front. Neurosci. 2018, 12, 541. [CrossRef]

34. Otte, C. Cognitive behavioral therapy in anxiety disorders: current state of the evidence. Dialogues Clin. Neurosci. 2011, 13, 413.

35. Piskosz, M. ReSound Relief: A Comprehensive Tool for Tinnitus Management. Audiol. Online 2017, 1-11.

36. Hesse, G. Smartphone app-supported approaches to tinnitus therapy. HNO 2018, 66, 350-357. [CrossRef] [PubMed]

37. Deshpande, A.K.; Shimunova, T. A Comprehensive Evaluation of Tinnitus Apps. Am. J. Audiol. 2019, $28,605-616$. [CrossRef] [PubMed]

38. Moher, D.; Liberati, A.; Tetzlaff, J.; Altman, D.G.; Group, T.P. Preferred Reporting Items for Systematic Reviews and Meta-Analyses: The PRISMA Statement. PLoS Med. 2009, 6, e1000097. [CrossRef] [PubMed]

39. Baxter, C.; Carroll, J.A.; Keogh, B.; Vandelanotte, C. Assessment of Mobile Health Apps Using Built-In Smartphone Sensors for Diagnosis and Treatment: Systematic Survey of Apps Listed in International Curated Health App Libraries. JMIR mHealth uHealth 2020, 8, e16741. [CrossRef]

40. Sterne, J.A.C.; Savović, J.; Page, M.J.; Elbers, R.G.; Blencowe, N.S.; Boutron, I.; Cates, C.J.; Cheng, H.Y.; Corbett, M.S.; Eldridge, S.M.; et al. RoB 2: A revised tool for assessing risk of bias in randomised trials. BMJ $2019,366$. [CrossRef]

41. Zeng, X.; Zhang, Y.; Kwong, J.S.; Zhang, C.; Li, S.; Sun, F.; Niu, Y.; Du, L. The methodological quality assessment tools for preclinical and clinical studies, systematic review and meta-analysis, and clinical practice guideline: A systematic review. J.-Evid.-Based Med. 2015, 8, 2-10. [CrossRef]

42. Newman, C.W.; Jacobson, G.P.; Spitzer, J.B. Development of the tinnitus handicap inventory. Arch. Otolaryngol. Head Neck Surg. 1996, 122, 143-148. [CrossRef]

43. Henry, J.A.; Griest, S.; Thielman, E.; McMillan, G.; Kaelin, C.; Carlson, K.F. Tinnitus Functional Index: Development, validation, outcomes research, and clinical application. Hear. Res. 2016, 334, 58-64. [CrossRef]

44. Kroenke, K.; Spitzer, R.L. The PHQ-9: A new depression diagnostic and severity measure. Psychiatr. Ann. 2002, 32, 509-515. [CrossRef]

45. Spitzer, R.L.; Kroenke, K.; Williams, J.B.; Löwe, B. A brief measure for assessing generalized anxiety disorder: the GAD-7. Arch. Intern. Med. 2006, 166, 1092-1097. [CrossRef] [PubMed]

46. Blei, D.M.; Ng, A.Y.; Jordan, M.I. Latent dirichlet allocation. J. Mach. Learn. Res. 2003, 3, $993-1022$.

47. Nie, N.H.; Bent, D.H.; Hull, C.H. SPSS: Statistical Package for the Social Sciences; McGraw-Hill: New York, NY, USA, 1975; Volume 227. 
48. Sabarish, A.; Kruthika, S. Efficacy of Sound Therapy Using Android Based Application in Individual with Tinnitus. 2019. Available online: https://www.researchgate.net/publication/331732699_EFFICACY_OF_ SOUND_THERAPY_USING_ANDROID_BASED_APPLICATION_IN_INDIVIDUAL_WITH_TINNITUS (accessed on 15 March 2012).

49. Tyler, R.S.; Owen, R.L.; Bridges, J.; Gander, P.E.; Perreau, A.; Mancini, P.C. Tinnitus suppression in cochlear implant patients using a sound therapy app. Am. J. Audiol. 2018, 27, 316-323. [CrossRef] [PubMed]

50. Kim, S.Y.; Chang, M.Y.; Hong, M.; Yoo, S.G.; Oh, D.; Park, M.K. Tinnitus therapy using tailor-made notched music delivered via a smartphone application and Ginko combined treatment: A pilot study. Auris Nasus Larynx 2017, 44, 528-533. [CrossRef]

51. Inkster, B.; Sarda, S.; Subramanian, V. An empathy-driven, conversational artificial intelligence agent (Wysa) for digital mental well-being: real-world data evaluation mixed-methods study. JMIR mHealth uHealth 2018, 6, e12106. [CrossRef]

52. Fitzpatrick, K.K.; Darcy, A.; Vierhile, M. Delivering cognitive behavior therapy to young adults with symptoms of depression and anxiety using a fully automated conversational agent (Woebot): a randomized controlled trial. JMIR Ment. Health 2017, 4, e19. [CrossRef]

53. Paul, A.M.; Fleming, C.E. Anxiety Management on Campus: An Evaluation of a Mobile Health Intervention. J. Technol. Behav. Sci. 2019, 4, 58-61. [CrossRef]

54. Henry, J.A.; Thielman, E.; Zaugg, T.; Kaelin, C.; Choma, C.; Chang, B.; Hahn, S.; Fuller, B. Development and field testing of a smartphone "App" for tinnitus management. Int. J. Audiol. 2017, 56, 784-792. [CrossRef]

55. McGuinness, L.A.; Higgins, J.P.T. Risk-of-bias VISualization (robvis): An R package and Shiny web app for visualizing risk-of-bias assessments. Res. Synth. Methods 2020. [CrossRef]

56. Okamoto, H.; Stracke, H.; Stoll, W.; Pantev, C. Listening to tailor-made notched music reduces tinnitus loudness and tinnitus-related auditory cortex activity. Proc. Natl. Acad. Sci. USA 2010, 107, 1207-1210. [CrossRef]

57. Stein, A.; Wunderlich, R.; Lau, P.; Engell, A.; Wollbrink, A.; Shaykevich, A.; Kuhn, J.T.; Holling, H.; Rudack, C.; Pantev, C. Clinical trial on tonal tinnitus with tailor-made notched music training. BMC Neurol. 2016, 16, 38. [CrossRef] [PubMed]

58. Deutsch, B.C.; Piccirillo, J.F. Momentary Analysis of Tinnitus: Considering the Patient; Springer: Berlin, Germany, 2020.

59. Hauptmann, C.; Wegener, A.; Poppe, H.; Williams, M.; Popelka, G.; Tass, P.A. Validation of a mobile device for acoustic coordinated reset neuromodulation tinnitus therapy. J. Am. Acad. Audiol. 2016, 27, 720-731. [CrossRef] [PubMed]

60. Jun, H.J.; Park, M.K. Cognitive behavioral therapy for tinnitus: evidence and efficacy. Korean J. Audiol. 2013, 17, 101. [CrossRef] [PubMed]

61. Martinez-Devesa, P.; Waddell, A.; Perera, R.; Theodoulou, M. Cognitive behavioural therapy for tinnitus. Cochrane Database Syst. Rev. 2007. [CrossRef]

62. Hesse, G. Evidence and evidence gaps in tinnitus therapy. GMS Curr. Top. Otorhinolaryngol. Head Neck Surg. 2016, 15, Doc04. [PubMed]

63. Robinson, S.K.; Viirre, E.S.; Bailey, K.A.; Kindermann, S.; Minassian, A.L.; Goldin, P.R.; Pedrelli, P.; Harris, J.P.; McQuaid, J.R. A randomized controlled trial of cognitive-behavior therapy for tinnitus. Int. Tinnitus J. 2008, 14, 119-126.

64. Kaldo, V.; Levin, S.; Widarsson, J.; Buhrman, M.; Larsen, H.C.; Andersson, G. Internet versus group cognitive-behavioral treatment of distress associated with tinnitus: a randomized controlled trial. Behav. Ther. 2008, 39, 348-359. [CrossRef]

65. Andersson, G.; Strömgren, T.; Ström, L.; Lyttkens, L. Randomized controlled trial of internet-based cognitive behavior therapy for distress associated with tinnitus. Psychosom. Med. 2002, 64, 810-816.

66. Kaldo-Sandstrom, V.; Larsen, H.C.; Andersson, G. Internet-Based Cognitive-Behavioral Self-Help Treatment of Tinnitus. Am. J. Audiol. 2004, 13, 185-192. [CrossRef]

67. Henry, J.; Zaugg, T.; Myers, P.; Kendall, C. Progressive Tinnitus Management. In Clinical Handbook for Audiologists Appendixes; VA Employee Education System: Long Beach, CA, USA, 2010; Volume 59, p. 97. 
68. Schmidt, C.J.; Kaelin, C.; Henselman, L.; Henry, J.A. Need for mental health providers in progressive tinnitus management: A gap in clinical care. Fed. Pract. 2017, 34, 6.

69. Edmonds, C.M.; Ribbe, C.; Thielman, E.J.; Henry, J.A. Progressive tinnitus management level 3 skills education: A 5-year clinical retrospective. Am. J. Audiol. 2017, 26, 242-250. [CrossRef] [PubMed]

70. Henry, J.A.; Thielman, E.J.; Zaugg, T.L.; Kaelin, C.; Schmidt, C.J.; Griest, S.; McMillan, G.P.; Myers, P.; Rivera, I.; Baldwin, R.; others. Randomized controlled trial in clinical settings to evaluate effectiveness of coping skills education used with progressive tinnitus management. J. Speech Lang. Hear. Res. 2017, 60, 1378-1397. [CrossRef] [PubMed]

71. Stoyanov, S.R.; Hides, L.; Kavanagh, D.J.; Wilson, H. Development and validation of the user version of the Mobile Application Rating Scale (uMARS). JMIR mHealth uHealth 2016, 4, e72. [CrossRef] [PubMed]

72. Levine, D.M.; Co, Z.; Newmark, L.P.; Groisser, A.R.; Holmgren, A.J.; Haas, J.S.; Bates, D.W. Design and testing of a mobile health application rating tool. NPJ Digit. Med. 2020, 3, 1-7. [CrossRef]

73. Schlee, W.; Hall, D.A.; Canlon, B.; Cima, R.F.; de Kleine, E.; Hauck, F.; Huber, A.; Gallus, S.; Kleinjung, T.; Kypraios, T.; others. Innovations in doctoral training and research on tinnitus: The European School on Interdisciplinary Tinnitus Research (ESIT) Perspective. Front. Aging Neurosci. 2018, 9, 447. [CrossRef]

Publisher's Note: MDPI stays neutral with regard to jurisdictional claims in published maps and institutional affiliations.

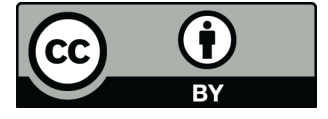

(C) 2020 by the authors. Licensee MDPI, Basel, Switzerland. This article is an open access article distributed under the terms and conditions of the Creative Commons Attribution (CC BY) license (http://creativecommons.org/licenses/by/4.0/). 